\title{
Haematology Symposium
}

\section{A symposium held on 4 November 201 I at the Royal College of Physicians of Edinburgh.}

\author{
J Easterbrook \\ Clinical Lecturer and Specialist Registrar in Haematology, Royal Infirmary of Edinburgh, \\ Edinburgh, Scotland, UK
}

DECLARATION OF INTERESTS No conflict of interests declared.

\author{
Correspondence to J Easterbrook, \\ Haematology Department, \\ Royal Infirmary of Edinburgh, \\ 5I Little France Crescent, Edinburgh, \\ Midlothian EHI6 4SA, UK
}

tel. +44 (0) I3I 5361000

e-mail

Jennifer.Easterbrook@ed.ac.uk
Haematology is a fast-moving speciality. Knowledge of haematological conditions and development of new treatments is advancing at a phenomenal rate. Thus, it is a perpetual challenge for both the specialist and general physician to stay abreast of the latest advances. This symposium covered a broad range of topics and provided an excellent general update on both clinical and scientific aspects of haematology.

\section{SESSION I: MANAGING HAEMATOLOGICAL MALIGNANCIES IN THE ELDERLY}

As the life expectancy of the population increases, the burden of haematological malignancy, particularly nonHodgkin lymphoma, is growing rapidly. The speakers addressed some of challenges facing the haematologist in managing elderly patients.

Dr Chris Fegan (Consultant Haematologist, University of Wales) opened the session with his talk on chronic lymphocytic leukaemia (CLL) in the elderly patient. He discussed the German CLL8 trial data in which the addition of rituximab to the standard first line regimen fludarabine-cyclophosphamide was shown to improve outcome.'

Dr Fiona Scott (Consultant Haematologist, Western General Hospital, Edinburgh) reviewed therapeutic approaches to elderly patients with diffuse large B-cell lymphoma. She urged us to consider functional status rather than age alone and alluded to the disappointing lack of robust trial data for the elderly population, a concern echoed by other speakers.

The median age of patients with myelodysplasia is 74 years. Approximately $70 \%$ of patients have 'low-risk' disease for which the mainstay of treatment is supportive care, predominantly with blood transfusions. In his review of the best supportive care for elderly patients with myelodysplasia, Professor David Bowen (St James Institute of Oncology, Leeds) focused on the European Leukaemia Registry Net data. He emphasised the finding that the median pre-transfusion haemoglobin for low-risk myelodysplasia patients $(n=1000)$ is actually only 8 grams per litre $(g / L)$, which suggests that currently most patients remain significantly anaemic despite red cell transfusion.

\section{SESSION 2: ANTICOGULANTS - NEW AND OLD}

The perioperative management of patients requiring temporary interruption of antithrombotic therapy, usually warfarin, for a surgical or other non-invasive procedure, is a commonly encountered clinical problem. 'Bridging anticoagulation' refers to the administration of short-acting anticoagulants such as subcutaneous lowmolecular weight heparin or intravenous heparin to 'bridge the gap' when the international normalised ratio (INR) is not therapeutic during this period. It is a controversial topic which lacks high quality evidence to guide optimal regimens, particularly for patients with mechanical valves. Professor Mike Greaves (Head of School of Medicine, University of Aberdeen) described the current evidence and discussed the 2008 American College of Chest Physicians (ACPP) guideline. ${ }^{2}$ The evidence suggests that warfarin therapy should not be interrupted for outpatient dental procedures if the INR $<4{ }^{3}$ However, in most other situations, the decision should be made on an individual basis, weighing up the perceived thromboembolic risk from discontinuing anticoagulation for an invasive procedure or surgery and the risk of bleeding due to heparin.

It may be that the new oral anticoagulants will simplify perioperative anticoagulation in the future. In his talk entitled 'Is warfarin dead?' Professor Sam Schulman (Professor of Medicine, Thrombosis Service, McMaster Clinic, Ontario, Canada) delivered a balanced view of the advantages and disadvantages of the new oral anticoagulants. However, he also argued that warfarin is inexpensive, it has a proven track record in trials for different clinical indications, it is a well tolerated drug and the need for INR testing facilitates monitoring of compliance. Despite the inevitable arrival of new oral anticoagulants into clinical practice, he therefore believes that warfarin will still be with us for at least another 5-10 years. 


\section{SESSION 3: MICRO RNAS AND EPIGENETICS IN CLINICAL PRACTICE}

MicroRNAs are small non-coding ribonucleic acid (RNA) molecules that negatively regulate the translation of Messenger RNA through a variety of mechanisms. Dr George Follows (Consultant Haematologist/Associate Lecturer,Addenbrooke's Hospital, Cambridge) described the expansion in our understanding of how microRNA networks are deregulated in a range of malignant and non-malignant conditions, which in the future may have significant impact on diagnosis, predicting prognosis and therapeutic targeting in clinical practice.

Epigenetics is the study of heritable changes in phenotype resulting from alterations in a chromosome without an accompanying change in the deoxyribonucleic acid (DNA) sequence. These changes are mainly acquired through DNA methylation or post-translational histone modification. Professor Alan Warren (MRC Laboratory of Molecular Biology and Department of Haematology, University of Cambridge) illustrated how such discoveries are driving 'epigenetic therapies' in haematology. For example the DNA hypomethylating agent, 5-azacytidine, is now used in clinical practice to treat myelodysplasia. ${ }^{4}$

\section{SESSION 4: HOW I MANAGE...}

Professor Mark Vickers (Department of Haematology, Aberdeen Royal Infirmary) discussed the pathogenesis, diagnosis and management of autoimmune haemolytic anaemia (AlHA). He highlighted that there has only ever been one non-randomised controlled trial for the treatment of AlHA. ${ }^{5}$ The current standard of care is firstline treatment with corticosteroids and second-line treatment remains a choice between splenectomy, rituximab and other immunosuppressive drugs.

Dr Lynn Manson (Consultant Haematologist, Scottish National Blood Transfusion Service, Edinburgh) outlined her personal management strategy for feto-maternal alloimmune thrombocytopenia. Due to lack of robust trial data, there is no international consensus as to the best antenatal management of the condition. She favours a risk-adapted non-invasive approach with maternal intravenous immunoglobulin (with or without prednisolone) as the mainstay of treatment and only considering fetal blood sampling and intrauterine platelet transfusions in the difficult, high-risk cases.
Dr David Wilks (Regional Infectious Disease Unit, Western General Hospital, Edinburgh) concluded the day with an entertaining talk on pyrexia of unknown origin. He described an evidence-based approach to its management and used a case to illustrate potential pitfalls. He urged us to remember that a therapeutic trial of antibiotics is rarely indicated, that a trial of steroids is almost never indicated and that imaging and biopsy are always the most useful steps in making a diagnosis.

\section{TAKE-HOME MESSAGE}

As we strive to keep up-to-date with the latest knowledge of conditions, therapeutics, trial data and ever expanding diagnostic tools, we were humbly reminded not to lose sight of the patient. We are treating an ageing population and need to find ways to individualise care to provide the maximum benefit for the patient. As the speciality continues to advance in the years to come this will undoubtedly be an increasing challenge for us all. We would do well to keep the maxim 'primum non nocere' ('first, do no harm') at the forefront of our minds.

\section{REFERENCES}

I Hallek M, Fischer K,Fingerle-Rowson G et al. Addition of rituximab to fludarabine and cyclophosphamide in patients with chronic lymphocytic leukaemia: a randomised, open-label, phase 3 trial. Lancet 2010; 376:1164-74. http://dx.doi.org/I0.1016/S0I40. 6736(I0)6I38I-5

2 Douketis JD, Berger PB, Dunn AS et al. The perioperative management of antithrombotic therapy: American College of Chest Physicians Evidence-Based Clinical Practice Guidelines (8th Edition). Chest 2008; 133:299-339S. http://dx.doi.org//0.1378/ chest.08-0675

3 Nematullah A, Alabousi A, Blanas $N$ et al. Dental surgery for patients on anticoagulant therapy with warfarin: a systematic review and meta-analysis. J Can Dent Assoc 2009; 75:4I.

4 Fenaux P, Mufti G], Hellstrom-Lindberg E et al. Efficacy of azacitidine compared with that of conventional care regimens in the treatment of higher-risk myelodysplastic syndromes: a randomised, open-label, phase III study. Lancet Oncol 2009; 10:22332. http://dx.doi.org//0.1016/SI470-2045(09)70003-8

5 Crowther M, Chan YL, Garbett IK et al. Evidence-based focused review of the treatment of idiopathic warm immune hemolytic anemia in adults. Blood 201 I; I 1 8:4036-40. http://dx.doi.org// 0.1 I82/ blood-20I I-05-347708 